\title{
REVIEW
}

\section{Health-related quality-of-life instruments for Alzheimer's disease and mixed dementia}

\author{
Jaime Perales, ${ }^{1,2}$ Theodore D. Cosco, ${ }^{2}$ Blossom C. M. Stephan, ${ }^{2}$ Josep Maria Haro ${ }^{1,3}$ \\ and Carol Brayne ${ }^{2}$ \\ ${ }^{1}$ Parc Sanitari Sant Foan de Déu, Universitat de Barcelona, Sant Boi de Llobregat, Barcelona, Spain \\ ${ }^{2}$ Department of Public Health and Primary Care, Cambridge Institute of Public Health, University of Cambridge, Cambridge, UK \\ ${ }^{3}$ Instituto de Salud Carlos III, Centro de Investigación Biomédica en Red de Salud Mental. CIBERSAM, Spain
}

Background: Over the last 20 years, a number of instruments developed for the assessment of health-related quality of life (HRQL) in dementia have been introduced. The aim of this review is to synthesize evidence from published reviews on HRQL measures in dementia and any new literature in order to identify dementia specific HRQL instruments, the domains they measure, and their operationalization.

Methods: An electronic search of PsycINFO and PubMed was conducted, from inception to December 2011 using a combination of key words that included quality of life and dementia.

Results: Fifteen dementia-specific HRQL instruments were identified. Instruments varied depending on their country of development/validation, dementia severity, data collection method, operationalization of HRQL in dementia, psychometric properties, and the scoring. The most common domains assessed include mood, self-esteem, social interaction, and enjoyment of activities.

Conclusions: A number of HRQL instruments for dementia are available. The suitability of the scales for different contexts is discussed. Many studies do not specifically set out to measure dementia-specific HRQL but do include related items. Determining how best to operationalize the many HRQL domains will be helpful for mapping measures of HRQL in such studies maximizing the value of existing resources.

Keywords: systematic review, psychometric properties, dimensions, operationalization, scales, mood

\section{Introduction}

Dementia is one of the most common disorders of old age (Ferri et al., 2005; Marengoni et al., 2008) and a leading cause of mortality and disability in high-income countries (Lopez et al., 2006). Medications temporarily reduce symptoms for some, but without modifying the underlying course of the disorder, which is related to many underlying causes. Narrow assessment of cognition and functional ability is insufficient for clinical decision-making and policy development as they only reflect a part of the impact of dementia (Whitehouse, 2000). Treatment is increasingly focused on improving or maintaining optimal quality of life (QoL; Ettema et al., 2005a) as

Correspondence should be addressed to: Jaime Perales, Department of Public Health and Primary Care, Cambridge Institute of Public Health, University Forvie Site, Robinson Way, Cambridge CB20SR, UK. Phone: +34 936406350 ext 12546; Email: jaume.perales@pssjd.org. Received 8 Nov 2012; revision requested 25 Nov 2012; revised version received 4 Dec 2012; accepted 4 Dec 2012. First published online 11 January 2013 this has become a key outcome for evaluating the effectiveness of dementia interventions (Small et al., 1997; Whitehouse, 2000; Moniz-Cook et al., 2008).

Health-related quality of life (HRQL) can be defined as the individual's perception of the impact of a health condition on everyday life (Bullinger et al., 1993). It differs from the concept of quality of life in that HRQL includes only aspects of quality of life that are affected by a health condition. Despite the lack of agreement of what domains constitute HRQL, most authors appear to agree upon the multidimensional and subjective nature of the concept and that the assessment should include measurement of positive and negative dimensions (Lawton, 1994; The WHOQOL Group, 1995; Brown et al., 2004; Ready, 2011).

Multiple measures have been developed specifically for assessing HRQL in patients with Alzheimer's disease or related dementias.

These instruments can be either generic HRQL questionnaires used in dementia populations such as the World Health Organization Quality of 
Life Assessment (WHOQOL) or Schedule for the Evaluation of Individual Quality of Life (SEIQoL; The WHOQOL Group, 1998; Schölzel-Dorenbos, 2000), dimension specific scales such as the Progressive deteriorations Scale (PDS) (DeJong et al., 1989) or dementia specific such as the Quality of Life in Alzheimer's Disease (QoL-AD) or the DEMQOL (Logsdon et al., 1999; Smith et al., 2005a). A number of studies have reviewed the different instruments used to measure HRQL in dementia (e.g. Ready and Ott, 2003; Ettema et al., 2005a). However, no attempt has been made as yet to synthesize the findings across the different reviews. Although one study has discussed the appropriateness of different scales (SchozelDorenbos et al., 2007), this did not use a systematic methodology. No review has assessed the features of the different scales in detail in order to assess their suitability in different contexts.

The aim of this paper is to synthesize the evidence from reviews on HRQL instruments for dementia and any new literature to bring together and provide an update on dementia-specific HRQL measures providing details of their features including: number of items, scoring, data-collection method, severity in which the instrument may be administered, domains, time frame, countries where the scales were developed or validated, and measures of reliability and validity. The suitability of the scales in different contexts is discussed. Conceptualization and operationalization of dementia-specific HRQL domains by each dementia-specific instrument are analyzed and compared for consistency.

\section{Methods}

In order to synthesize the evidence from reviews on HRQL instruments in dementia, J. Perales conducted an electronic search in PubMed from inception to December 2011 using a combination of key words that included quality of life and dementia as major topic Mesh terms and specifying reviews as type of publication. The publications could be in either English or Spanish language.

In order to identify previous and new literature, a second electronic search was conducted of PsycINFO and PubMed, from inception to December 2011 using a combination of words that included quality of life and dementia as major topic Mesh terms or keywords. The criteria for inclusion were: (i) papers, abstracts or scale manuals that were published in English or Spanish language on dementiaspecific HRQL measures developed for use with on patients with $\mathrm{AD}$ or mixed dementia; and (ii) reporting on the development, description of the dimensions, and psychometric properties of an instrument. In order to report country of validation of the scales, those papers with abstracts in English irrespective of the rest of the text were also included. Generic, domain-specific QoL measures such as those measuring only activities of daily living (DeJong et al., 1989) and Parkinson's disease-specific HRQL measures are beyond the scope of this review and were excluded. This review excluded considerations of caregiver quality of life except where this was related to measures of patient HRQL.

Literature selection was undertaken in two phases. In phase 1 , titles and abstracts of all papers were independently reviewed (J. Perales and T.D. Cosco) to exclude non-related publications. Fulltext papers accepted in phase 1 were reviewed in order to extract the appropriate information (phase 2 ). In case of discrepancy, if no agreement was met by both readers after discussion, a third author would decide (B.C.M. Stephan). In order to rate the psychometric quality assessment of each of the instruments, standardized criteria was used. These criteria are shown in Table 1.

\section{Results}

\section{Reviews identified (literature search 1)}

Of the 271 papers identified in the first literature search, eight were reviews on HRQL instruments in dementia (Salek et al., 1998; Walker et al., 1998; Ready and Ott, 2003; Ettema et al., 2005a; Smith et al., 2005a; Lucas-Carrasco, 2007; SchozelDorenbos et al., 2007; Ready, 2011). Only four (Salek et al., 1998; Walker et al., 1998; Ready and Ott, 2003; Ettema et al., 2005a) used a systematic approach. Table 2 shows the dementia-specific HRQL instruments included in each of the eight reviews identified. Although the number of reviews increases by year of publication, there are some inconsistencies in the instruments included. The reviews highlight the wide variation in instruments, their items, and methods of scoring, psychometric properties, data collection method, severity of dementia, and the populations used to assess validity and reliability.

\section{Instruments identified (literature search 2)}

Figure 1 shows the selection process for the review on dementia-specific HRQL. In total, 848 papers were identified. After the title-abstract screen, 76 papers remained. Based on the fulltext search, 68 publications covering 15 different dementia-specific HRQL scales were identified and included in this review. The dementia-specific HRQL measures reviewed included: the Alzheimer Disease Related Quality of Life (ADRQL), Bath 
Table 1. Psychometric criteria

\begin{tabular}{|c|c|c|}
\hline $\begin{array}{l}\text { PSYCHOMETRIC } \\
\text { PROPERTY }\end{array}$ & DEFINITION/TEST & CRITERIA FOR ACCEPTABILITY \\
\hline Item analysis/reduction & $\begin{array}{l}\text { Identification of items for possible elimination } \\
\text { owing to weak psychometric performance; } \\
\text { assessed on the basis of (1) unrotated } \\
\text { principal component factor analysis to } \\
\text { determine whether all items are measuring a } \\
\text { single factor and (2) item analyses for all items }\end{array}$ & $\begin{array}{l}\text { Principal component factor analysis: } \\
\text { All items should load on the first unrotated } \\
\text { factor }>0.30 \\
\text { Item analyses (applied to all items): } \\
\text { Missing data }<5 \% \\
\text { No item redundancy (inter-item } \\
\text { correlations } \leq 0.75 \text { ) } \\
\text { Item-total correlations }>0.25 \\
\text { Maximum endorsement frequencies } \leq 80 \% \\
\text { (i.e. the proportion of respondents who } \\
\text { endorse each response category), } \\
\text { including floor/ceiling effects }<80 \% \text { (i.e. } \\
\text { response categories with high } \\
\text { endorsement rates at the bottom/top } \\
\text { ends of the scale, respectively) Aggregate } \\
\text { adjacent endorsement frequencies } \geq 10 \%\end{array}$ \\
\hline Acceptability & $\begin{array}{l}\text { The quality of data; assessed by completeness of } \\
\text { data and score distributions }\end{array}$ & $\begin{array}{l}\text { Missing data for summary scores }<5 \% \\
\text { Even distribution of endorsement } \\
\text { frequencies across response categories } \\
\text { Floor ceiling effects for summary scores } \\
\quad<10 \%\end{array}$ \\
\hline
\end{tabular}

Reliability

Internal consistency

Test-retest

Inter-rater

Parallel (alternative) forms

Validity

Content

Criterion related

Concurrent

Predictive
The extent to which items comprising a scale measure the same construct (e.g. homogeneity of the scale); assessed by Cronbach's $\alpha$ and item-total correlations

The stability of a measuring instrument; assessed by administering the instrument to respondents on two different occasions and examining the correlation between test and retest scores

Agreement between independent raters/observers; assessed by ICCs

Agreement between two or more parallel/alternative forms or different versions of the same measure (e.g. form $\mathrm{A} / \mathrm{B}$, short/long form) that indicates that they can be used interchangeably; assessed on the basis of correlations between parallel/ alternative forms of a measure

The extent to which the content of a scale is representative of the conceptual domain it is intended to cover; assessed qualitatively during the questionnaire development stage through pretesting with patients, expert opinion, and literature review

Evidence that the scale predicts a gold-standard criterion that is measured at the same time; assessed on the basis of correlations between the scale and the criterion measure.

Evidence that the scale predicts a gold-standard criterion that is measured in the future; assessed on the basis of correlations between the scale and the criterion measure.
Cronbach's $\alpha$ for summary scores $\geq 0.70$

Item-total correlations $\geq 0.20$

Test-retest reliability correlations for summary scores $\geq 0.70$

ICC $\geq 0.70$

High correlations between parallel/alternative forms of the measure (e.g. between long and short form)

Qualitative evidence from pretesting with patients, expert opinion, and literature review that items in the scale are representative of the construct being measured

High correlation between the scale and the criterion measure

High correlation between the scale and the criterion measure 
Table 1. Continued.

\begin{tabular}{|c|c|}
\hline $\begin{array}{l}\text { PSYCHOMETRIC } \\
\text { PROPERTY }\end{array}$ & DEFINITION/TEST \\
\hline \multicolumn{2}{|l|}{ Construct validity } \\
\hline Within-scale analyses & $\begin{array}{l}\text { Evidence that a single entity (construct) is being } \\
\text { measured and that items can be combined to } \\
\text { form a summary score; assessed on the basis } \\
\text { of evidence of good internal consistency and } \\
\text { correlations between scale scores (which } \\
\text { purport to measure related aspects of the } \\
\text { construct) }\end{array}$ \\
\hline \multicolumn{2}{|l|}{$\begin{array}{l}\text { Analyses against } \\
\text { external criteria }\end{array}$} \\
\hline Convergent & $\begin{array}{l}\text { Evidence that the scale is correlated with other } \\
\text { measures of the same or similar constructs; } \\
\text { assessed on the basis of correlations between } \\
\text { the measure and other similar measures }\end{array}$ \\
\hline Discriminant & $\begin{array}{l}\text { Evidence that the scale is not correlated with } \\
\text { measures of different constructs; assessed on } \\
\text { the basis of correlations with measures of } \\
\text { different constructs }\end{array}$ \\
\hline $\begin{array}{l}\text { Known groups } \\
\text { differences }\end{array}$ & $\begin{array}{l}\text { The ability of a scale to differentiate known } \\
\text { groups; assessed by comparing scores for } \\
\text { subgroups who are expected to differ on the } \\
\text { construct being measured }\end{array}$ \\
\hline Responsiveness & $\begin{array}{l}\text { The ability of a scale to detect clinically } \\
\text { important change over time; assessed by } \\
\text { comparing scores before and after an } \\
\text { intervention of known efficacy (on the basis of } \\
\text { various methods including } t \text { tests, effect sizes, } \\
\text { standardized response means, or } \\
\text { responsiveness statistics) }\end{array}$ \\
\hline
\end{tabular}

CRITERIA FOR ACCEPTABILITY

Internal consistency (Cronbach's $\alpha$ ) $\geq 0.70$

Moderate to high correlations between scale scores

Correlations are expected to vary according to the degree of similarity between the constructs that are being measured by each instrument. Specific hypotheses are formulated and predictions tested on the basis of correlations

Low correlations between the instrument and measures of different constructs

Significant differences between known groups or difference of expected magnitude

Significant differences between known groups or difference of expected magnitude

Adapted from Smith et al. (2005a).

Assessment of Subjective Quality of Life in Dementia (BASQUID), Cornell-Brown Scale for Quality of Life in Dementia (CBS), Dementia Care Mapping (DCM), Dementia Quality of Life Instrument (D-QoL), DEMQOL, Patient Activity Scale-AD plus the Modified Apparent Emotion Scale (PES-AD + AES), Quality of Life in Late-stage Dementia Scale (QUALID), QoL-AD, Quality of Life Assessment Schedule (QOLAS), Quality of Life for Dementia (QoL-D), QUALIDEM, Quality of Life for Older People Experiencing Dementia (QLDJ), Vienna List, and the Community Dementia Quality of Life Profile. As shown in Table 2, none of the reviews included the QLDJ or identified all the instruments. Table 3 shows the publications reviewed for each of the instruments. Some publications have assessed the psychometric properties of more than one instrument at a time (Edelman et al., 2005; Sloane et al., 2005; Smith et al., 2005a).

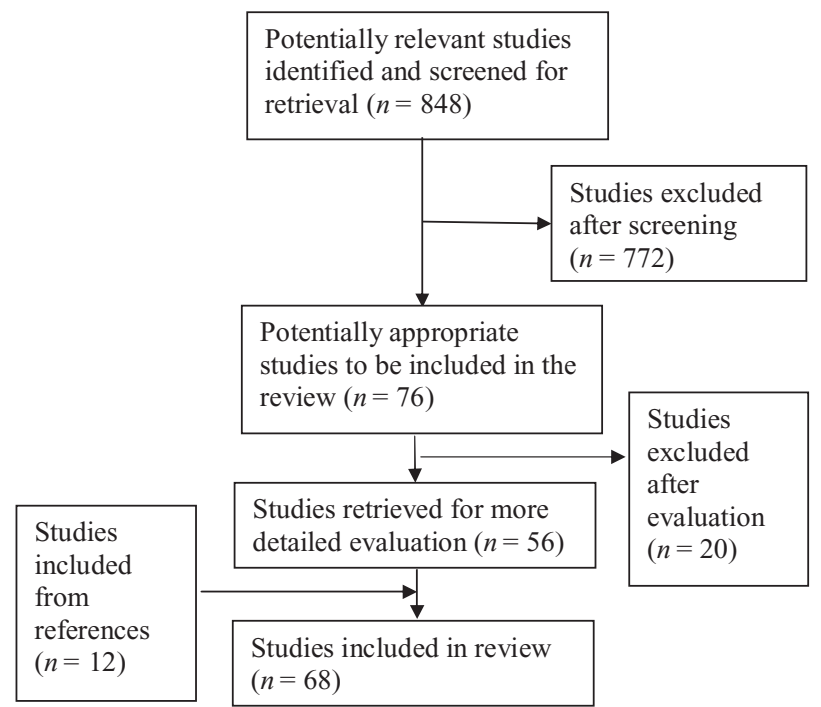

Figure 1. Flow chart of paper selection for the review on dementiaspecific health-related quality-of-life instruments. 
Table 2. Dementia-specific HRQL instruments included in each of the eight reviews identified in our search

\begin{tabular}{|c|c|c|c|c|c|c|c|}
\hline SCALE/REVIEW & $\begin{array}{l}\text { WALKER } \\
\text { AND } \\
\text { SALEK } \\
(1998)^{a, b}\end{array}$ & $\begin{array}{l}\text { READY } \\
(2003)^{c}\end{array}$ & $\begin{array}{l}\text { ETTEMA } \\
(2005 a)^{d}\end{array}$ & $\begin{array}{l}\text { SMITH } \\
(2005 a)^{e}\end{array}$ & $\begin{array}{l}\text { LUCAS- } \\
\text { CARRASCO } \\
(2007)^{f}\end{array}$ & $\begin{array}{l}\text { SCHOZEL- } \\
\text { DORENBOS } \\
\left(\begin{array}{llll}2 & 0 & 0 & 0\end{array}\right)^{\mathrm{g}}\end{array}$ & $\begin{array}{l}\text { READY } \\
(2011)^{h}\end{array}$ \\
\hline D-QoL & $x$ & $x$ & $x$ & $x$ & $x$ & $\times$ & $x$ \\
\hline QoL-AD & $x$ & $x$ & $x$ & $x$ & $x$ & $x$ & $x$ \\
\hline DCM & $x$ & $x$ & $x$ & & $x$ & & $x$ \\
\hline CBS & & $x$ & $x$ & & $x$ & $x$ & $x$ \\
\hline QOLAS & & $x$ & & $x$ & $x$ & & $x$ \\
\hline ADRQL & & $x$ & $x$ & $x$ & $x$ & $x$ & $x$ \\
\hline QUALID & & $x$ & & & $x$ & & $x$ \\
\hline QoL-D & & & $x$ & $x$ & $x$ & & \\
\hline DEMQOL & & & & $x$ & $x$ & $x$ & $x$ \\
\hline QUALIDEM & & & & & & $x$ & $x$ \\
\hline BASQID & & & & & & & $x$ \\
\hline \multicolumn{8}{|l|}{ QLDJ } \\
\hline PES-AD+AES & $x$ & $x$ & & $x$ & $x$ & & $x$ \\
\hline CDQLP & $x$ & & & $x$ & & & \\
\hline Vienna List & & & & & & $x$ & \\
\hline
\end{tabular}

a Salek et al. (1998); ${ }^{\mathrm{b}}$ Walker et al. (1998); ${ }^{\mathrm{c}}$ Ready and Ott (2003); ${ }^{\mathrm{d}}$ Ettema et al. (2005a); ${ }^{\mathrm{e}}$ Smith et al. (2005a); ${ }^{\mathrm{f}}$ Lucas-Carrasco (2007); ${ }^{\mathrm{g}}$ Schozel-Dorenbos et al. (2007); ${ }^{\text {h Ready (2011). }}$

ADRQL: Alzheimer Disease Related Quality of Life; BASQID: The Bath Assessment of Subjective Quality of Life in Dementia; CDQLP: The Community Dementia Quality of Life Profile; CBS: Cornell-Brown Scale for Quality of Life in Dementia; DCM: Dementia Care Mapping; D-QoL: Dementia Quality of Life Instrument; QLDJ: Quality of Life for Older People Experiencing Dementia; QoL-AD: Quality of Life in Alzheimer's Disease; QoL-D: Quality of Life for Dementia; QOLAS: Quality of Life Assessment Schedule; QUALID: Quality of Life in Late-Stage Dementia Scale.

\section{Instrument features}

Table 4 summarizes the characteristics of the original version of each of the 15 different instruments and reports the existence of validations in other countries. There are two instruments where only self-report is possible, six proxy-reportonly measures, four measures that include both self and proxy ratings, and three observer-rated instruments. The number of items varies between 10 in the QOLAS and 47 in the ADRQL. Three scales can obtain both total and subscale scores whereas six can only obtain subscale scores and six only total scores. Response scales vary from being binary to six-point Likert scales. Most response scales of observation-rated measures or those rated only by proxies ask about frequency of a certain behavior, whereas the other types of instruments vary between quality, how much of a problem, satisfaction, or worry of a trait. The psychometric properties of self-report only measures (Brod et al., 1999; Trigg et al., 2007a) have been tested in patients with mild-moderate dementia severity as have all measures using both types of report except for DEMQOL-proxy and QoL-AD. Two proxyreport only (Salek et al., 1997; Black et al., 1999) and two observer-rated instruments (Fossey et al., 2002; Ettema and Lange, 2007) have tested their psychometric properties in patients of all dementia severity whereas the psychometric properties of the rest have been tested in patients with moderatesevere dementia severity. The time frame of the questions is usually either in the present or in the previous week/two weeks. The number of dimensions ranges from two in the case of the DCM and PES-AD+AES to 13 in the QoL-AD. Most instruments have been developed in the USA (6) (Albert et al., 1996; Black et al., 1999; Brod et al., 1999; Logsdon et al., 1999; Weiner et al., 2000; Ready et al., 2002) or the UK (5) (Salek et al., 1997; Selai et al., 2001a; Fossey et al., 2002; Smith et al., 2005a; Trigg et al., 2007b). However, other instruments have also been developed in Japan (2) (Terada et al., 2002; Yamamoto-Mitani et al., 2002), the Netherlands (1) (Ettema et al., 2007) and Austria (1) (Porzsolt et al., 2004). Five instruments (Brod et al., 1999; Logsdon et al., 1999; Weiner et al., 2000; Fossey et al., 2002; Smith et al., 2005a) have been validated in other countries. None of the samples used to assess the psychometric properties of each of the instruments were population based.

\section{Conceptualization and operationalization}

The most common domains across different dementia-specific HRQL instruments are mood, social interaction, enjoyment of activities/sense of aesthetics, and self-esteem/self-concept. Other common domains are cognition, activities, health, living conditions, and feelings of usefulness. 
Table 3. Primary and secondary papers on dementia-specific HRQL measures identified in our search

\begin{tabular}{|c|c|c|}
\hline INSTRUMENT & $\begin{array}{l}\text { PRIMARY PAPERS } \\
\text { (DEVELOPMENT) }\end{array}$ & $\begin{array}{l}\text { SECONDARY PAPERS } \\
\text { (MODIFICATIONS } \\
\text { AND VALIDATIONS } \\
\text { IN OTHER } \\
\text { COUNTRIES) }\end{array}$ \\
\hline Alzheimer Disease Related Quality of Life (ADRQL) & 1,2 & $3,4,5,6$ \\
\hline Bath Assessment of Subjective Quality of Life in Dementia (BASQID) & 7,8 & \\
\hline Cornell-Brown Scale for Quality of Life in Dementia (CBS) & 9 & \\
\hline Community Dementia Quality of Life Profile (CDQLP) & $10-14$ & \\
\hline Dementia Care Mapping (DCM) & 15 & 5,1618 \\
\hline DEMQOL & 19,20 & 21,22 \\
\hline Dementia Quality of Life Instrument (D-QoL) & 23 & $5,6,19,24-32,33$ \\
\hline $\begin{array}{l}\text { Patient Activity Scale-AD plus the Modified Apparent Emotion Scale } \\
\text { (PES-AD + AES) }\end{array}$ & 34,35 & 5 \\
\hline Quality of Life for Older People Experiencing Dementia (QLDJ) & 36,37 & \\
\hline Quality of Life-Alzheimer's Disease (QoL-AD) & 38,39 & $6,19,40-56$ \\
\hline Quality of Life Assessment Schedule (QOLAS) & 57 & \\
\hline Quality of Life for Dementia (QoL-D) & 58 & \\
\hline Quality of Life in Late-stage Dementia Scale (QUALID) & 59 & $60-64$ \\
\hline QUALIDEM & $65-67$ & \\
\hline Vienna List & 68 & \\
\hline
\end{tabular}

References. 1: Rabins et al. (1999); 2: Black et al. (1999); 3: Kasper et al. (2009); 4: Black et al. (2009); 5: Sloane et al. (2005); 6: Edelman et al. (2005); 7: Trigg et al. (2007a); 8: Trigg et al. (2007b); 9: Ready et al. (2002); 10: Salek et al. (1999); 11: Salek et al. (1996); 12: Walker et al. (2001a); 13: Walker et al. (2001b); 14: Salek et al. (1997); 15: Fossey et al. (2002); 16: Sloane et al. (2007); 17: Suzuki et al. (2008); 18: Brooker and Surr (2006); 19: Smith et al. (2005a); 20: Smith et al. (2005b); 21: Smith et al. (2007); 22: Lucas-Carrasco et al. (2010); 23: Brod et al. (1999); 24: Adler and Resnick (2010); 25: Lucas-Carrasco et al. (2011); 26: Chiu et al. (2008); 27: Chiu et al. (2010); 28: Karim et al. (2008); 29: Ready et al. (2007); 30: Suzuki et al. (2005); 31: Suzuki et al. (2006); 32: Bosboom and Jonkers (2001); 33: Porzsolt et al. (2004); 34: Albert et al. (1996); 35: Albert et al. (2001); 36: Yamamoto-Mitani et al. (2002); 37: Yamamoto-Mitani et al. (2004); 38: Logsdon et al. (1999); 39: Logsdon et al. (2002); 40: León-Salas et al. (2011); 41: Chan et al. (2011); 42: Fuh and Wang (2006); 43: Hoe et al. (2005); 44: Lin Kiat Yap et al. (2008); 45: Matsui et al. (2006); 46: Hao-ying and Guo-dong (2005); 47: Rosas-Carrasco et al. (2010); 48: Shin (2006); 49: Novelli et al. (2010); 50: Novelli et al. (2005); 51: Patterson et al. (2006); 52: Revell et al. (2009); 53: Selai et al. (2001b); 54: Thorgrimsen et al. (2003); 55: Wolak et al. (2009); 56: Merchant et al. (2004); 57: Selai et al. (2001a); 58: Terada et al. (2002); 59: Weiner et al. (2000); 60: Barca et al. (2011); 61: Falk et al. (2007); 62: Garre-Olmo et al. (2010); 63: Martin-Cook et al. (2005); 64: Schalkwijk et al. (2009); 65: Ettema et al. (2007); 66: Bouman et al. (2011); 67: Ettema and Lange (2007); 68: Porzsolt et al. (2004).

Domains are operationalized differently across instruments. Most domains are operationalized either through the patient or proxy's perception of the different domains or through the rating of observational behaviors or contexts.

Most instruments measure mood as positive and negative affect although two exceptions are the QoL-AD, which asks for mood in general, and the QOLAS, which needs to be given two examples within the mood domain by the respondent. Common items on positive affect are cheerfulness, happiness, contentment, and calm. The most common items indicating negative effect are sadness, anger, worry, and anxiety. Proxy and observation-based instruments usually measure either observational indicators of patient's mood (such as crying) or proxy's perception of the patient's mood. A similar trend can be observed in other dimensions. For example, social interaction has been assessed as the perception by the patient or the proxy of the patient's quality of interactions such as worries about not having enough company, satisfaction or problems with social relationships, or through observation-based ratings such as frequency of visiting friends, talking or seeking or rejecting contact with people. Enjoyment of activities has been measured through perception, satisfaction, or worry about enjoyment of different activities, or observation-based assessments such as voluntarily participation in activities and talking about work or activities. A special case is the domain sense of aesthetics, which has been defined as the ability to enjoy sensory stimuli. Items on self-esteem involve perceptions of usefulness, selfconfidence, and satisfaction with oneself. Observerbased ratings consist usually in noticing that patients mention they are worthless, hopeless, or useless. Some questionnaires such as the ADRQL measure awareness of self with items such as responding to one's own name. Some instruments also include activities of daily living in their assessment of HRQL. These items have been measured as the patient or proxy's perception of the ability to do chores such as walking, cooking, eating, 


\begin{tabular}{|c|c|c|c|c|c|c|c|c|}
\hline MEASURE & $\begin{array}{l}\text { NO. OF } \\
\text { ITEMS }\end{array}$ & SCORING & RESPONSE SCALE & SEVERITY & TIME FRAME & DIMENSIONS & $\begin{array}{l}\text { VALIDATED } \\
\text { IN } \\
\text { POPULATION } \\
\text { STUDIES }\end{array}$ & $\begin{array}{l}\text { COUNTRY OF } \\
\text { VALIDATION }\end{array}$ \\
\hline \multicolumn{9}{|l|}{ Self-rated only } \\
\hline BASQID & 14 & $\begin{array}{l}\text { Total and } \\
\text { subscales }\end{array}$ & $\begin{array}{l}5 \text { point (not at all } \\
\text { satisfied-extremely } \\
\text { satisfied) and (not } \\
\text { at all-a great deal }\end{array}$ & Mild-moderate & Present & $\begin{array}{l}\text { Life satisfaction, feelings of } \\
\text { positive QoL }\end{array}$ & No & UK (original) \\
\hline D-QoL & 29 & Subscales & $\begin{array}{l}5 \text { point (never-very } \\
\text { often) and (not at } \\
\text { all-very) }\end{array}$ & Mild-moderate & Recently & $\begin{array}{l}\text { Positive affect, negative } \\
\text { affect, feelings of } \\
\text { belonging, self-esteem, } \\
\text { sense of aesthetics }\end{array}$ & No & $\begin{array}{l}\text { USA (original), China, } \\
\text { Japan, Spain, UK, } \\
\text { Netherlands }\end{array}$ \\
\hline \multicolumn{9}{|l|}{$\begin{array}{l}\text { Patient and } \\
\text { proxy rated }\end{array}$} \\
\hline CBS & 19 & Total & $\begin{array}{l}5 \text { point (negative } \\
\text { end-positive end) }\end{array}$ & Mild-moderate & Previous week & $\begin{array}{l}\text { Positive affect, negative } \\
\text { affect, satisfactions, } \\
\text { physical complaints }\end{array}$ & No & USA (original) \\
\hline DEMQOL & $\begin{array}{l}28(\mathrm{p}) \\
31(\mathrm{c})\end{array}$ & Total & $\begin{array}{l}4 \text { point (a lot-not at } \\
\text { all) }\end{array}$ & $\begin{array}{l}\text { Mild-moderate } \\
\text { (p) all stages } \\
\text { (c) }\end{array}$ & Previous week & $\begin{array}{l}\text { Daily activities, health and } \\
\text { well-being, cognitive } \\
\text { functioning, social } \\
\text { relationships, self-concept }\end{array}$ & No & UK (original), Spain \\
\hline QoL-AD & 12 & Total & $\begin{array}{l}4 \text { point } \\
\quad \text { (poor-excellent) }\end{array}$ & All stages & Present & $\begin{array}{l}\text { Physical health, energy, } \\
\text { mood, living situation, } \\
\text { memory, family, } \\
\text { marriage, friends, self as a } \\
\text { whole, ability to do chores } \\
\text { around the house, ability } \\
\text { to do things for fun, } \\
\text { money, QoL as a whole }\end{array}$ & No & $\begin{array}{l}\text { USA (original), China } \\
\text { (Cantonese and } \\
\text { Mandarin), Taiwan, } \\
\text { Spain, Japan, Brazil, } \\
\text { Korea, France, (and } \\
\text { French Switzerland), } \\
\text { Mexico, UK }\end{array}$ \\
\hline QOLAS & 10 & Total & $\begin{array}{l}6 \text { point (no } \\
\text { problem-it could } \\
\text { not be worse) }\end{array}$ & Mild-moderate & Present & $\begin{array}{l}\text { Physical, psychological, } \\
\text { social/family, usual } \\
\text { activities, cognitive } \\
\text { functioning }\end{array}$ & No & UK (original) \\
\hline \multicolumn{9}{|l|}{$\begin{array}{l}\text { Proxy-rated } \\
\text { only }\end{array}$} \\
\hline ADRQL & 47 & $\begin{array}{l}\text { Total and } \\
\text { subscales }\end{array}$ & $\begin{array}{l}\text { Dichotomous } \\
\quad \text { (agree/disagree) }\end{array}$ & All stages & Previous 2 weeks & $\begin{array}{l}\text { Social interaction, } \\
\text { awareness of self, feelings } \\
\text { and mood, enjoyment of } \\
\text { activities, response to } \\
\text { surroundings }\end{array}$ & No & USA (original) \\
\hline
\end{tabular}


Table 4. Continued.

\begin{tabular}{|c|c|c|c|c|c|c|c|c|}
\hline MEASURE & $\begin{array}{l}\text { NO. OF } \\
\text { ITEMS }\end{array}$ & SCORING & RESPONSE SCALE & SEVERITY & TIME FRAME & DIMENSIONS & $\begin{array}{l}\text { VALIDATED } \\
\text { IN } \\
\text { POPULATION } \\
\text { STUDIES }\end{array}$ & $\begin{array}{l}\text { COUNTRY OF } \\
\text { VALIDATION }\end{array}$ \\
\hline QLDJ & 24 & $\begin{array}{l}\text { Total and } \\
\text { subscales }\end{array}$ & $\begin{array}{l}4 \text { point (not at all } \\
\text { applicable, very } \\
\text { much applicable) }\end{array}$ & $\begin{array}{l}\text { Moderate- } \\
\text { severe }\end{array}$ & Previous 2 weeks & $\begin{array}{l}\text { Interacting with } \\
\text { surroundings, } \\
\text { expressing self, } \\
\text { experiencing minimum } \\
\text { negative behaviors }\end{array}$ & No & Japan (original) \\
\hline QUALID & 11 & Total & $\begin{array}{l}5 \text { point (different } \\
\text { options of } \\
\text { frequency) }\end{array}$ & $\begin{array}{l}\text { Moderate- } \\
\text { severe }\end{array}$ & Previous week & $\begin{array}{l}\text { Affect, comfort, and } \\
\text { engagement with } \\
\text { activities }\end{array}$ & No & $\begin{array}{l}\text { USA (original), Sweden, } \\
\text { Spain }\end{array}$ \\
\hline \multicolumn{9}{|l|}{$\begin{array}{c}\text { Observational } \\
\text { assessment }\end{array}$} \\
\hline DCM & 26 & Subscales & $\begin{array}{l}\text { Well-being: } 6 \text { point } \\
\text { (extreme } \\
\text { ill-being-extreme } \\
\text { well-being) }\end{array}$ & All stages & $\begin{array}{l}\text { Every } 5 \text { minutes } \\
\text { for } 6 \text { hours }\end{array}$ & Well-being, activity & No & UK (original), Japan \\
\hline
\end{tabular}


and shopping or how much problem or worry these activities involve. The same applies to the assessment of cognitive functioning. Other domains that have not been included so often include selfrated health, financial, and living context.

\section{Psychometric properties}

Table 5 shows the psychometric quality assessment using the criteria shown in Table 1 . Ten instruments (Albert et al., 1996; Salek et al., 1997; Black et al., 1999; Logsdon et al., 1999; Weiner et al., 2000; Selai et al., 2001a; Fossey et al., 2002; Ready et al., 2002; Yamamoto-Mitani et al., 2002; Porzsolt et al., 2004) either were not tested for acceptability or did not meet the criteria. Regarding reliability, all instruments but PES-AD+AES, DCM, and DEMQOL-Proxy show good evidence of internal consistency. Eight instruments (Salek et al., 1997; Brod et al., 1999; Logsdon et al., 1999; Weiner et al., 2000; Yamamoto-Mitani et al., 2002; Smith et al., 2005a; Ettema et al., 2007; Trigg et al., 2007b) showed good evidence of test-retest reliability. Among those instruments assessed by a proxy or an observer, six instruments assessed inter-rater reliability, most of them showing good evidence. Regarding validity, ten instruments showed good evidence of content validity (Salek et al., 1997; Black et al., 1999; Brod et al., 1999; Logsdon et al., 1999; Selai et al., 2001 a; Terada et al., 2002; Yamamoto-Mitani et al., 2002; Smith et al., 2005a; Ettema et al., 2007; Trigg et al., 2007b). Despite the fact that criterion-related validity cannot be tested due to the lack of a gold standard, two measures (Selai et al., 2001a; Ready et al., 2002) claim to show some evidence of it, perhaps referring to convergent validity. Regarding analyses against external criteria, 14 instruments (Albert et al., 1996; Salek et al., 1997; Black et al., 1999; Brod et al., 1999; Logsdon et al., 1999; Weiner et al., 2000; Selai et al., 2001a; Fossey et al., 2002; Ready et al., 2002; Terada et al., 2002; Porzsolt et al., 2004; Smith et al., 2005a; Ettema et al., 2007; Trigg et al., 2007b) show evidence of convergent validity but not discriminant or known groups differences. Six measures have shown responsiveness (DQoL, BASQID, QoL-AD, ADRQL, QUALID, and DCM). Finally, the factorial structure of nine instruments has been analyzed (Brod et al., 1999; Salek et al., 1999; Weiner et al., 2000; Fossey et al., 2002; Terada et al., 2002; Yamamoto-Mitani et al., 2002; Smith et al., 2005a; Trigg et al., 2007b; Revell et al., 2009), most of them finding subscales.

\section{Discussion}

This review synthesizes the information on dementia specific HRQL instruments from reviews 


\begin{tabular}{|c|c|c|c|c|c|c|c|c|c|c|c|}
\hline MEASURE & ACCEPTABILITY & $\begin{array}{l}\text { INTERNAL } \\
\text { CONSISTENCY }\end{array}$ & $\begin{array}{l}\text { TEST- } \\
\text { RETEST }\end{array}$ & $\begin{array}{l}\text { INTER-RATER } \\
\text { RELIABILITY }\end{array}$ & $\begin{array}{l}\text { CONTENT } \\
\text { VALIDITY }\end{array}$ & $\begin{array}{l}\text { CRITERION- } \\
\text { RELATED } \\
\text { VALIDITY }\end{array}$ & $\begin{array}{l}\text { CONVERGENT } \\
\text { VALIDITY } \\
\text { Na }\end{array}$ & $\begin{array}{l}\text { DISCRIMINANT } \\
\text { VALIDITY }\end{array}$ & $\begin{array}{l}\text { KNOWN } \\
\text { GROUPS } \\
\text { DIFFERENCES }\end{array}$ & RESPONSIVENESS & $\begin{array}{l}\text { FACTOR OR } \\
\text { PRINCIPAL } \\
\text { COMPONENTS } \\
\text { ANALYSIS }\end{array}$ \\
\hline \multicolumn{12}{|l|}{ Self-rated only } \\
\hline BASQID & ++ & +++ & +++ & NA & +++ & - & +++ & ++ & - & Yes & Yes \\
\hline D-QoL & ++ & +++ & +++ & NA & +++ & - & ++ & - & ++ & - & Yes \\
\hline \multicolumn{12}{|l|}{$\begin{array}{l}\text { Patient and } \\
\text { proxy rated }\end{array}$} \\
\hline CBS & - & +++ & - & $\mathrm{NA}(\mathrm{c}) /+++(\mathrm{p})$ & - & + & ++ & - & - & - & - \\
\hline DEMQOL & $++(\mathrm{c})(+++(\mathrm{p})$ & $+++(\mathrm{c})(++(\mathrm{p})$ & +++ & $\mathrm{NA}(\mathrm{c})(-(\mathrm{p})$ & +++ & - & ++ & ++ & $-(\mathrm{c})(+(\mathrm{p})$ & - & Yes \\
\hline QoL-AD & - & +++ & +++ & $\mathrm{NA}(\mathrm{c}) /-(\mathrm{p})$ & +++ & - & +++ & - & $-(\mathrm{c}) /+++(\mathrm{p})$ & Yes & Yes \\
\hline QOLAS & - & +++ & - & $\mathrm{NA}(\mathrm{c}) /-(\mathrm{p})$ & +++ & + & ++ & - & ++ & - & - \\
\hline MEASURE & ACCEPTABILITY & $\begin{array}{l}\text { INTERNAL } \\
\text { CONSISTENCY }\end{array}$ & $\begin{array}{l}\text { TEST- } \\
\text { RETEST }\end{array}$ & $\begin{array}{l}\text { INTER-RATER } \\
\text { RELIABILITY }\end{array}$ & $\begin{array}{l}\text { CONTENT } \\
\text { VALIDITY }\end{array}$ & $\begin{array}{l}\text { CRITERION- } \\
\text { RELATED } \\
\text { VALIDITY }\end{array}$ & $\begin{array}{l}\text { CONVERGENT } \\
\text { VALIDITY } \\
\text { VA.............. }\end{array}$ & $\begin{array}{l}\text { DISCRIMINANT } \\
\text { VALIDITY }\end{array}$ & $\begin{array}{l}\text { KNOWN } \\
\text { GROUPS } \\
\text { DIFFERENCES }\end{array}$ & RESPONSIVENESS & $\begin{array}{l}\text { FACTOR OR } \\
\text { PRINCIPAL } \\
\text { COMPONENTS } \\
\text { ANALYSIS }\end{array}$ \\
\hline \multicolumn{12}{|l|}{$\begin{array}{l}\text { Proxy rated } \\
\text { only }\end{array}$} \\
\hline ADRQL & - & +++ & - & - & +++ & - & +++ & - & - & Yes & - \\
\hline CDQLP & - & +++ & +++ & - & +++ & - & + & - & - & - & Yes \\
\hline PES- & - & - & ++ & - & - & - & + & - & - & Yes & - \\
\hline \multicolumn{12}{|l|}{$\mathrm{AD}+\mathrm{AES}$} \\
\hline QLDJ & - & +++ & +++ & ++ & +++ & - & - & ++ & + & - & Yes \\
\hline QoL-D & +++ & +++ & - & +++ & +++ & - & ++ & - & - & - & Yes \\
\hline QUALID & - & +++ & +++ & +++ & - & - & +++ & ++ & - & Yes & Yes \\
\hline \multicolumn{12}{|l|}{$\begin{array}{r}\text { Observational } \\
\text { assessment }\end{array}$} \\
\hline DCM & - & + & + & - & - & + & ++ & - & - & Yes & Yes \\
\hline & ++ & +++ & +++ & ++ & +++ & - & +++ & +++ & - & - & - \\
\hline QUALIDEM & & & & & & & & & & & \\
\hline Vienna List & - & +++ & - & ++ & + & - & ++ & - & - & - & - \\
\hline
\end{tabular}

$\mathrm{p}=$ patient version; $\mathrm{c}=$ caregiver version.

CRITERIA

- No evidence or not tested.

+ Some limited evidence

EXAMPLE

++ Some good evidence but some aspect do not meet criteria or some aspects not tested/reported +++ Good evidence

ADRQL did not assess acceptability

CDQLP only reported the $p$ value when examining the association

between the total score and the MMSE score

DEMQOL's acceptability: missingness is always higher than 5\%

although there is no floor or ceiling effect.

DEMQOL proxy's acceptability: missingness is always lower than

$5 \%$ and there are no floor or ceiling effects.

NA, not applicable

Inter-rater reliability in self-rated scales

ADRQL: Alzheimer Disease-Related Quality of Life; BASQID: The Bath Assessment of Subjective Quality of Life in Dementia; CDQLP: The Community Dementia Quality of Life Profile; CBS: Cornell-Brown Scale for Quality of Life in Dementia; DCM: Dementia Care Mapping; D-QoL: Dementia Quality of Life Instrument; QLDJ: Quality of Life for Older People Experiencing Dementia; QoL-AD: Quality of Life in Alzheimer's Disease; QoLAS: Quality of Life Assessment Schedule; QUALID: Quality of Life in Late-stage Dementia Scale. 
(Salek et al., 1998; Walker et al., 1998; Ready and Ott, 2003; Ettema et al., 2005a; Smith et al., 2005a; Lucas-Carrasco, 2007; Schozel-Dorenbos et al., 2007; Ready, 2011) and builds on these by gathering them all into a single study and identifying one new measure, the QLDJ.

While this is a systematic review, we did not include measures assessing only a specific domain of HRQL such as the PDS (DeJong et al., 1989), or generic HRQL scales that are not tailored to people with dementia (Rabins et al., 1999; Silberfeld et al., 2002). Their focus on health and function imply that HRQL will decrease automatically with disease progression (Ettema et al., 2005a) and some of these lack evidence on validity or reliability in dementia populations (Ettema et al., 2005a). We also did not include instruments that measure the QoL of caregivers of people with dementia as these are outside the scope of this review. The literature searches were conducted in English and in Anglophone databases and, therefore, instruments developed in non-English-speaking countries without a translation available would have been missed. However, regarding instrument development and validation, we accepted any publication as long as the abstract was in English or Spanish.

\section{Conceptualization and operationalization}

The concept of HRQL in dementia has been influenced by the broader concept of QoL that refers to "evaluation by subjective and social-normative criteria, of the behavioral and environmental situation of a person" (Lawton, 1994). There has been a movement in QoL toward the measurement of the experience of the person, including usually perceptions or satisfactions with psychological, physical, and social domains (Ettema et al., 2005b). In dementia-specific HRQL instruments, the measurement is also aimed at capturing the experience of the person with dementia. Domains commonly measured are mood, self-esteem, social interaction, and enjoyment of activities. Similarly to the general concept of QoL, normative measures such as income or cognitive tests (different to perception or satisfaction with such domains) have been excluded and considered as a different outcome (Brod et al., 1999; Rabins et al., 1999). Conceptual frameworks do not differ in essence with Lawton's model of HRQL in dementia (Lawton, 1994), although they limit the number of domains. Different perspectives on HRQL abound and are manifest in the variety of domains represented in the different scales. For example, the measurement of HRQL using the ADRQL will widely differ to the one using the CDQLP since they have very few domains in common. Instruments also differ in their breadth of the assessment and whether subjective experience of the person with dementia is assessed or proxy measures (observational or not) are used instead. While self-reported measures are more appropriate for measuring the patient's own experience, in severe stages, the use of instruments based on proxy ratings is inevitable. Further, we found that there is no single protocol for assessing the different domains across instruments. This limits cross-study comparability.

\section{Country of development and validation}

Most dementia-specific HRQL measures were developed in the USA and UK. A number of scales have been validated in other countries such as Spain and Japan (Suzuki et al., 2005, 2006; Matsui et al., 2006), increasing the availability. The QoL$\mathrm{AD}$ has been validated in at least ten different countries and the D-QoL has been validated in at least five different countries in the Americas, Europe, and Asia. This allows for cross-county comparisons. However, the concept of HRQL may vary across different cultures and culturally specific scales may also be needed. Further, for validation studies is the issue of the representativeness of samples used in development and validations studies. None of the 15 instruments have been developed using a population-based sample raising issues of generalizability.

\section{Dementia severity}

Decisions for scale selection will depend on the dementia severity. Self-rated instruments would be more appropriate for mild-moderate stages and proxy and observer-rated instruments more appropriate at more severe stages of the disease. Most of the extant dementia-specific HRQL measures are proxy rated. This is a consequence of the idea that people with dementia are not able to rate their own HRQL due to cognitive impairment. However, there is a strong movement in measurement of HRQL in dementia to obtain self-reports from the individual with dementia where possible given recent findings that suggest that people with mild to moderate dementia are aware and able to assess their HRQL (Brod et al., 1999; Mozley et al., 1999; Selai et al., 2001a; Logsdon et al., 2002; Ready et al., 2002; Smith et al., 2005a; Trigg et al., 2007b). Proxy informants have a different point of view on the patient's HRQL and tend to give lower rating than people with dementia (Logsdon et al., 2002; Thorgrimsen et al., 2003). Even with careful training of observers, it is uncertain whether the observed behaviors represent 
the most important and relevant aspects of HRQL, as these measures have been developed to assess the subjective perceptions of QoL. However, it has been shown that proxies are as good as patients in detecting changes in HRQL over time (Sneeuw et al., 1997). Studies suggest that these differences in reporting can be explained by the disability paradox, caregiver states such as depression or burden and the lack of patient's insight (Carr and Higginson, 2001; Logsdon et al., 2002; Novella et al., 2012), but also by methodological issues such as precision bias or response bias (Smith et al., 2005a). Obtaining information from both sources (patients and caregivers) is important since they reflect different and imperfect measurements of "true" state and may be contrasted, providing richer information. A different approach is assessing HRQL using different instruments covering all dementia severities (Edelman et al., 2005); however, this method can be confusing since different conceptual frameworks are assumed when using different measures.

\section{Purpose of assessment}

Instruments may be used for clinical practice or for research. For clinical practice, since the main aim is to help the individual to continue living in the optimal fashion, the optimal scale will be the one that lets the persons with dementia assess a personal perception of HRQL allowing a more individualized and, therefore, effective treatment plan. To date, there is only one scale that allows this type of assessment, the QOLAS (Selai et al., 2001a). This is a double edged sword since a drawback of this measure in research is that, for this same reason, scores of the different participants or the same participant in different stages might not reflect the same concept of HRQL and, therefore, comparisons do not seem to be completely pertinent. This raises the question of whether people can learn to consider certain aspects when assessing their HRQL and dismiss others. This would be useful for improving HRQL in dementia.

For cross-sectional studies, operationalization, country of development/validation and data collection method will guide the selection of the scale. However, when it comes to longitudinal designs, the use of proxy and observer-rated scales seems more appropriate since severity of dementia is likely to change over time. For both longitudinal and randomized control trials, responsiveness is an important factor. To date, at least six instruments have proved to have a certain degree of responsiveness or sensitivity to change. These measures are the BASQID,
QoL-AD, ADRQL, QUALID, PES-AD+AES, and DCM. (Black et al., 1999; Albert et al., 2001; Fossey et al., 2002; Thorgrimsen et al., 2003; Martin-Cook et al., 2005; Trigg et al., 2007b).

\section{Psychometric properties}

Almost every measure showed good evidence of internal consistency, and most measures have at least tested reliability in two different ways. All self-rated instruments and one scale of each of the other data collection methods showed at least some good evidence of acceptability. These scales are the D-QoL and BASQID for self-rated, DEMQOL for both self and proxy rated, and QoL-D and QUALIDEM for proxy-rated. Content validity has been mostly reached by qualitative evidence from pretesting with patients, expert opinion, and literature review that items in the scale are representative of the construct. In-depth qualitative interviews with people with dementia and/or their carers were conducted for the D-QoL, DEMQOL, BASQID, ADRQL, QUALIDEM, and QoL-D in order to generate the scale items. A special case is the QOLAS, in which the items are tailored to each respondent. Although two measures (Selai et al., 2001a; Ready et al., 2002) claim to measure it, criterion-related validity cannot be assessed due to the lack of a gold standard with which to compare it. Convergent validity has mainly been assessed by means of correlations between the scales and measures of dementia severity (Albert et al., 1996; Salek et al., 1996; Brod et al., 1999; Rabins et al., 1999; Weiner et al., 2000; Selai et al., 2001a; Ready et al., 2002; Yamamoto-Mitani et al., 2002; Porzsolt et al., 2004; Smith et al., 2005a; Ettema et al., 2007; Trigg et al., 2007b), depression (Rabins et al., 1999; Selai et al., 2001a; Logsdon et al., 2002; Smith et al., 2005a; Ettema et al., 2007), activities of daily living (Rabins et al., 1999; Weiner et al., 2000; Selai et al., 2001a; Logsdon et al., 2002; Terada et al., 2002; Yamamoto-Mitani et al., 2002; Porzsolt et al., 2004; Smith et al., 2005a), behavioral and psychological symptoms (Weiner et al., 2000; Ettema et al., 2007), and other measures of QoL (Fossey et al., 2002; Smith et al., 2005a; Trigg et al., 2007b). Discriminant validity has not often been assessed and usually includes associations with gender, age, or caregiver characteristics.

\section{Scoring}

A profile score or subscales of nine out of 15 instruments can be obtained. Within these nine, three (ADRQL, QLDJ, and BASQID) (Rabins et al., 1999; Yamamoto-Mitani et al., 2002; Trigg et al., 2007b) can also calculate a total HRQL score. The possibility of calculating subscale scores is vital 
for the assessment of HRQL. First, because HRQL is by definition a multidimensional concept and, therefore, the scores should represent each domain. Second, if HRQL is to be used in order to assess treatment benefits, subscale scores may shape those treatments.

\section{Conclusion}

There has been much development on the measurement of dementia-specific HRQL in the last two decades. This is perhaps due to the lack of consensus on the concept of HRQL in dementia. It is also a reflection of the importance of assessing HRQL in this group of people (Karlawish et al., 2000; Whitehouse, 2000; Moniz-Cook et al., 2008). The fact that dementia may be expressed in many different ways makes the concept of HRQL in dementia even more complex. The suitability of the scale depends on several factors; namely countries (development/validation), dementia severity (mild, moderate, or severe), data collection method (patient, proxy, both, or observer rating), purpose of the assessment (clinical practice, research), conceptualization and operationalization (domains and items), psychometric properties (validity and reliability), and scoring (total scores vs. subscales). Many studies do not specifically set out to measure dementia-specific HRQL but do include related items as part of their surveys that together may function as a HRQL scale (e.g. items on depression, social interaction, or enjoyment of activities). This paper may also be useful for mapping HRQL dimensions in such studies maximizing the value of existing resources. In order to do so, item analyses could determine the performance of frequently used questions in dementia HRQL instruments. These items could also be mapped onto already existing conceptual frameworks. The items to be used will depend on how severe the dementia is and how the information was administered. However, validity and reliability will have to be analyzed if this is to be conducted. Future studies validating each scale across samples (community vs. clinical), populations, and cohorts are needed to be able to generalize results.

\section{Conflict of interest}

None.

\section{Description of authors' roles}

J. Perales conducted literature review, the data collection, and wrote the paper. T.D. Cosco conducted the literature review and assisted with writing the paper. B.C.M. Stephan supervised the data collection and assisted with writing the paper. J.M. Haro assisted with writing the paper. C. Brayne supervised the data collection, development of the paper, and assisted with writing the paper.

\section{Acknowledgments}

J. Perales is grateful to the Instituto de Salud Carlos III for a predoctoral grant (PFIS) and to Professors Betty E. Black and Sam Salek for providing additional literature.

\section{References}

Adler, E. and Resnick, B. (2010). Reliability and validity of the dementia quality of life measure in nursing home residents. Western fournal of Nursing Research, 32, 686-704.

Albert, S. M. et al. (1996). Quality of life in patients with Alzheimer's disease as reported by patient proxies. Fournal of the American Geriatrics Society, 44, 1-12.

Albert, S. M. et al. (2001). Longitudinal study of quality of life in people with advanced Alzheimer's disease. American Fournal of Geriaric Psychology, 9, 160-168.

Barca, M. L., Engedal, K., Laks, J. and Selbaek, G. (2011). Quality of life among elderly patients with dementia in institutions. Dementia and Geriatric Cognitive Disorders, 31, 435-442.

Black, B. S., Rabins, P. V. and Kasper, J. D. (1999). Alzheimer Disease Related Quality of Life (ADRQL): User's Manual, 1st edn. Baltimore, MD: DEMeasure.

Black, B., Rabins, P. and Kasper, J. (2009). Alzheimer Disease Related Quality of Life: User's Manual, 2nd edn. Baltimore, MD: DEMeasure.

Bosboom, P. R. and Jonkers, C. (2001). Dutch version of the $D Q o L$. Amsterdam: EMGO Institute, VU University.

Bouman, A. I. E. et al. (2011). Evaluation of QUALIDEM: a dementia-specific quality of life instrument for persons with dementia in residential settings; scalability and reliability of subscales in four Dutch field surveys. International Fournal of Geriatric Psychiatry, 26, 711-722.

Brod, M., Stewart, A. L., Sands, L. and Walton, P. (1999). Conceptualization and measurement of quality of life in dementia: the dementia quality of life instrument (DQoL). The Gerontologist, 39, 25-35.

Brooker, D. J. and Surr, C. (2006). Dementia Care Mapping (DCM): initial validation of DCM 8 in UK field trials. International fournal of Geriatric Psychiatry, 1018-1025.

Brown, J., Bowling, A. and Flynn, T. (2004). Models of quality of life: a taxonomy, overview and systematic review of the literature. Review: Literature and Arts of the Americas, $1,12-48$.

Bullinger, M., Anderson, R., Cella, D. and Aaronson, N. (1993). Developing and evaluating cross-cultural instruments from minimum requirements to optimal models. Quality of Life Research, 2, 451-459.

Carr, A. J. and Higginson, I. J. (2001). Are quality of life measures patient centred? BMF, 322, 1357-1360. 
Chan, I. W. P., Chu, L. W., Lee, P. W. H., Li, S. W. and Yu, K. K. (2011). Effects of cognitive function and depressive mood on the quality of life in Chinese Alzheimer's disease patients in Hong Kong. Geriatrics and Gerontology International, 11, 69-76.

Chiu, Y., Shyu, Y. and Huang, H. (2008). Measure of quality of life for Taiwanese persons with early to moderate dementia and related factors. International fournal of Geriatric Psychiatry, 23, 580-585.

Chiu, Y. C., Chiu, Y. F., Hsu, W. C., Lee, S. H., Chen, S. T. and Kao, H. Y. (2010). Developing a Chinese quality of life in dementia instrument for patients with early-to-moderate dementia: an exploratory test of validity. Fournal of Clinical Nursing, 19, 2174-2184.

DeJong, R., Osterlund, O. W. and Roy, G. W. (1989). Measurement of quality-of-life changes in patients with Alzheimer's disease. Clinical Therapeutics, 11, 545-554.

Edelman, P., Fulton, B. R., Kuhn, D. and Chang, C. H. (2005). A comparison of three methods of measuring dementia-specific quality of life: perspectives of residents, staff, and observers. The Gerontologist, 45 Spec No, 27-36.

Ettema, T. P. and Lange, J. D. (2007). QUALIDEM: development and evaluation of a dementia specific quality of life instrument. Scalability, reliability and internal structure. International journal of geriatric psychiatry, 22, 549-556.

Ettema, T. P., Dröes, R.-M., de Lange, J., Mellenbergh, G. J. and Ribbe, M. W. (2005a). A review of quality of life instruments used in dementia. Quality of Life Research, 14, 675-686.

Ettema, T. P., Dröes, R.-M., de Lange, J., Ooms, M. E., Mellenbergh, G. J. and Ribbe, M. W. (2005b). The concept of quality of life in dementia in the different stages of the disease. International Psychogeriatrics, 17, 353.

Ettema, T. P., Droes, R.-M., de Lange, J., Mellenbergh, G. J. and Ribbe, M. W. (2007). QUALIDEM: development and evaluation of a dementia specific quality of life instrument - validation. International Fournal of Geriatric Psychiatry, 22, 424-430.

Falk, H., Persson, L.-O. and Wijk, H. (2007). A psychometric evaluation of a Swedish version of the Quality of Life in Late-Stage Dementia (QUALID) scale. International Psychogeriatrics, 19, 1040-1050.

Ferri, C. P. et al. (2005). Global prevalence of dementia: a Delphi consensus study. Lancet, 366, 2112-2117.

Fossey, J., Lee, L. and Ballard, C. (2002). Dementia Care Mapping as a research tool for measuring quality of life in care settings: psychometric properties. International fournal of Geriatric Psychiatry, 17, 1064-1070.

Fuh, J. L. and Wang, S. J. (2006). Assessing quality of life in Taiwanese patients with Alzheimer's disease. International Fournal of Geriatric Psychiatry, 21, 103-107.

Garre-Olmo, J. et al. (2010). Cross-cultural adaptation and psychometric validation of a Spanish version of the Quality of Life in Late-Stage Dementia Scale. Quality of Life Research, 19, 445-453.

Hao-ying, H. and Guo-dong, M. (2005). Reliabilities and validities of the Quality of Life-Alzheimer's Disease (QoL-AD) Scale. Chinese fournal of Clinical Psychology, 13, 402-404.

Hoe, J., Katona, C., Roch, B. and Livingston, G. (2005). Use of the QOL-AD for measuring quality of life in people with severe dementia: the LASER-AD study. Age and Ageing, 34, 130-135.

Karim, S., Ramanna, G., Petit, T., Doward, L. and Burns, A. (2008). Development of the Dementia Quality of Life questionnaire (D-QOL): UK version. Aging and Mental Health, 12, 144-148.

Karlawish, J. H. T., Klocinski, J. L., Merz, J., Clark, C. M. and Asch, D. A. (2000). Caregivers' preferences for the treatment of patients with Alzheimer's disease. Neurology, 55, 1008-1014.

Kasper, J. D., Black, B. S., Shore, A. D. and Rabins, P. V. (2009). Evaluation of the validity and reliability of the Alzheimer Disease-related Quality of Life Assessment Instrument. Alzheimer Disease and Associated Disorders, 23, 275-284.

Lawton, M. P. (1994). Quality of life in Alzheimer disease. Alzheimer Disease and Associated Disorders, 8, 138-150.

León-Salas, B., Logsdon, R. G., Olazarán, J., Martínez-Martín, P. and The, M. A. (2011). Psychometric properties of the Spanish QoL-AD with institutionalized dementia patients and their family caregivers in Spain. Aging and Mental Health, 15, 775-783.

Lin Kiat Yap, P. et al. (2008). How do Chinese patients with dementia rate their own quality of life? International Psychogeriatrics, 20, 482-493.

Logsdon, R. G., Gibbons, L. E., McCurry, S. M. and Teri, L. (1999). Quality of life in Alzheimer's disease: patient and caregiver reports. Fournal of Mental Health and Ageing, 5, 21-32.

Logsdon, R. G., Gibbons, L. E., McCurry, S. M. and Teri, L. (2002). Assessing quality of life in older adults with cognitive impairment. Psychosomatic Medicine, 64, 510-9.

Lopez, A. D., Mathers, C. D., Ezzati, M., Jamison, D. T. and Murray, C. J. L. (2006). Global and regional burden of disease and risk factors, 2001: systematic analysis of population health data. Lancet, 367, 1747-1757.

Lucas-Carrasco, R. (2007). Calidad de vida y demencia. Medicina Clínica, 128, 70-75.

Lucas-Carrasco, R., Lamping, D. L., Banerjee, S., Rejas, J., Smith, S. C. and Gómez-Benito, J. (2010). Validation of the Spanish version of the DEMQOL system. International Psychogeriatrics, 22, 589-597.

Lucas-Carrasco, R., Gómez-Benito, J., Rejas, J. and Brod, M. (2011). The Spanish version of the dementia quality of life questionnaire: a validation study. Aging and Mental Health, 15, 482-489.

Marengoni, A., Winblad, B., Karp, A. and Fratiglioni, L. (2008). Prevalence of chronic diseases and multimorbidity among the elderly population in Sweden. American fournal of Public Health, 98, 1198-1200.

Martin-Cook, K., Hynan, L. S., Rice-Koch, K., Svetlik, D. A. and Weiner, M. F. (2005). Responsiveness of the quality of life in late-stage dementia scale to psychotropic drug treatment in late-stage dementia. Dementia and Geriatric Cognitive Disorders, 19, 82-85.

Matsui, T. et al. (2006). Determinants of the quality of life in Alzheimer's disease patients as assessed by the Japanese version of the quality of Life-Alzheimer's disease scale. Dementia and Geriatric Cognitive Disorders, 21, 182-191.

Merchant, C., Hope, K. W. and Hope, K. (2004). The quality of life in Alzheimer's disease scale: direct 
assessment of people with cognitive impairment. International fournal of Older People Nursing, 13, 105110.

Moniz-Cook, E. et al. (2008). A European consensus on outcome measures for psychosocial intervention research in dementia care. Aging and Mental Health, 12, 14-29.

Mozley, C. G. et al. (1999). 'Not knowing where I am doesn't mean I don't know what I like': cognitive impairment and quality of life. International fournal of Geriatric Psychiatry, 14, 776-783.

Novelli, M. M. P. C., Dal Rovere, H., Nitrini, R. and Caramelli, P. (2005). Cross-cultural adaptation of the quality of life assessment scale on Alzheimer disease. Arquivos de Neuro-Psiquiatria, 63, 201-206.

Novelli, M. M. P. C., Nitrini, R. and Caramelli, P. (2010). Validation of the Brazilian version of the quality of life scale for patients with Alzheimer's disease and their caregivers (QOL-AD). Aging and Mental Health, 14, 624-631.

Novella, J. L., Jochum, C., Jolly, D., Morrone, I., Bureau, J. A. F. and Blanchard, F. (2012). Agreement between patients' and proxies' reports of quality of life in Alzheimer's disease. Quality of Life Research, 10, 443-452.

Patterson, M. B. et al. (2006). ADCS Prevention instrument project: Quality of Life Assessment (QOL). Alzheimer Disease and Associated Disorders, 20, 179-190.

Porzsolt, F., Kojer, M., Schmidl, M., Greimel, E. R., Sigle, J., Richter, J. and Eisemann, M. (2004). A new instrument to describe indicators of well-being in old-old patients with severe dementia - the Vienna List. Health and Quality of Life Outcomes, 2, 10.

Rabins, P. V., Kasper, J. D., Kleinman, L. and Black, B. S. (1999). Concepts and methods in the development of the ADRQL: an instrument of assessing health-related quality of life in persons with Alzheimer's disease. Fournal of Mental Health and Ageing, 5, 33-48.

Ready, R. E. (2011). Measuring quality of life in dementia. In C. Jenkinson, P. Michele and M. B. Bromber (eds.), Quality of Life Measurement in Neurodegenerative and Related Conditions (pp. 82-94). Cambridge: Cambridge University Press.

Ready, R. E. and Ott, B. R. (2003). Quality of life measures for dementia. Health and Quality of Life Outcomes, 1, 11.

Ready, R. E., Ott, B. R., Grace, J. and Fernandez, I. (2002). The Cornell-Brown scale for quality of life in Dementia. Alzheimer Disease and Associated Disorders, 16, 109-115.

Ready, R. E., Ott, B. R. and Grace, J. (2007). Factor structure of patient and caregiver ratings on the dementia quality of life instrument. Neuropsychology, development, and cognition. Section B, Aging, Neuropsychology and Cognition, 14, 144-154.

Revell, A. J., Caskie, G. I., Willis, S. L. and Schaie, K. W. (2009). Factor structure and invariance of the Quality of Life in Alzheimer' s Disease (QoL-AD) Scale. Experimental Aging Research, 35, 250-267.

Rosas-Carrasco, O., Torres-Arreola, L. D. P., Guerra-Silla, M. D. G., Torres-Castro, S. and Gutierrez-Robledo, L. M. (2010). Validation of the Quality of Life in Alzheimer's Disease (QOL-AD) scale in Mexican patients with Alzheimer, vascular and mixed-type dementia. Revista de Neurologia, 51, 804-808.
Salek, M., Schwartzberg, A. and Bayer, A. (1996). Evaluating health-related quality of life in patients with dementia: development of a proxy self-administered questionnaire. Pharmacy World and Science, 18, A6.

Salek, S. S., Ramgoolam, N., Edwards, S., Luscambe, D. and Bayer, A. (1997). Quality of Life in Alzheimer's Disease: Reliability of a Dementia-Specific Measure (CDQLP). In the 26th European Symposium on Clinical Pharmacy. Tours, Loire Valley.

Salek, S. S., Walker, M. D. and Bayer, A. J. (1998). A review of quality of life in Alzheimer's disease Part 2: Issues in Assessing Drug Effects. PharmacoEconomics, 14, 613-627.

Salek, M., Walker, M. and Bayer, A. (1999). The community dementia quality of life profile (CDQLP): a factor analysis. Quality of Life Research, 8, 660.

Schalkwijk, D., Verlare, L. R., Muller, M. T., Knol, D. L. and Van Der Steen, J. T. (2009). [Measuring quality of life in nursing home residents with severe dementia: psychometric properties of the QUALID scale]. Tijdschrift voor Gerontologie en Geriatrie, 40, 184-192.

Schölzel-Dorenbos, C. J. (2000). Measurement of quality of life in patients with dementia of Alzheimer type and their caregivers: Schedule for the Evaluation of Individual Quality of Life (SEIQoL). Tijdschrift voor Gerontologie en Geriatrie, 31, 23-26.

Schozel-Dorenbos, C. J. M. et al. (2007). Evaluating the outcome of interventions on quality of life in dementia: selection of the appropriate scale. International fournal of Geriatric Psychiatry, 511-519.

Selai, C. E., Trimble, M. R., Rossor, M. N. and Harvey, R. J. (2001a). Assessing quality of life in dementia: preliminary psychometric testing of the Quality of Life Assessment Schedule (QOLAS). Neuropsychological Rehabilitation, 11, 219-243.

Selai, C., Vaughan, A., Harvey, R. J. and Logsdon, R. (2001b). Using the QOL-AD in the UK. International Fournal of Geriatric Psychiatry, 16, 537-538.

Shin, H. Y. (2006). A preliminary study on the Korean version of quality of life-Alzheimer's disease (QOL-AD) scale in community-dwelling elderly with dementia. fournal of Preventive Medicine and Public Health Yebang Uihakhoe Chi, 39, 243-248.

Silberfeld, M., Rueda, S., Krahn, M. and Naglie, G. (2002). Content validity for dementia of three generic preference based health related quality of life instruments. Quality of Life Research, 11, 71-79.

Sloane, P. D., Zimmerman, S., Williams, C. S., Reed, P. S., Gil, K. S. and Preisser, J. S. (2005). Evaluating the quality of life of long-term care residents with dementia. The Gerontologist, 45, 37-49.

Sloane, P. D. et al. (2007). Dementia care mapping as a research tool. International fournal of Geriatric Psychiatry, 22, 580-589.

Small, G. W. et al. (1997). Diagnosis and treatment of Alzheimer disease and related disorders. Consensus statement of the American Association for Geriatric Psychiatry, the Alzheimer's Association, and the American Geriatrics Society. FAMA, 278, 1363-1371.

Smith, S. et al. (2005a). Measurement of health-related quality of life for people with dementia: development of a new instrument (DEMQOL) and an evaluation of current 
methodology. Health Technology Assessment (Winchester, England), 9, 1-93.

Smith, S. et al. (2005b). What constitutes health-related quality of life in dementia? Development of a conceptual framework for people with dementia and their carers. International fournal of Geriatric Psychiatry, 20, 889-895.

Smith, S. et al. (2007). Development of a new measure of health-related quality of life for people with dementia: DEMQOL. Psychological Medicine, 37, 737-746.

Sneeuw, K. C. et al. (1997). The use of significant others as proxy raters of the quality of life of patients with brain cancer. Medical Care, 35, 490-506.

Suzuki, M., Uchida, A., Kanamori, M. and Ooshiro, H. (2005). Development of the Dementia quality of life instrument-Japanese version. Nihon Ronen Igakkai Zasshi, 42, 423-431.

Suzuki, M., Kanamori, M., Greiner, C., Ito, K. and Ooshiro, H. (2006). Follow-up study on subjective quality of life for elderly persons with dementia using the Japanese version of Dementia Quality of Life Instrument (JDQoL). Nihon Ronen Igakkai Zasshi fapanese fournal of Geriatrics, 43, 485-491.

Suzuki, M. et al. (2008). Dementia Care Mapping-Japanese version(DCM-J) as a research evaluation method for measuring quality of life among elderly patients with dementia: reliability and validity of Well-being and Ill-being value. Nihon Ronen Igakkai Zasshi fapanese fournal of Geriatrics, 45, 68-76.

Terada, S. et al. (2002). Development and evaluation of a health-related quality of life questionnaire for the elderly with dementia in Japan. International fournal of Geriatric Psychiatry, 17, 851-858.

The WHOQOL Group. (1995). The World Health Organization Quality of Life Asessment (WHOQOL): Position Paper From The World Health Organization. Social Science and Medicine, 41, 1403-1409.

The WHOQOL Group. (1998). Development of the World Health Organization WHOQOL-BREF quality of life assessment. Psychological Medicine, 28, 551-558.

Thorgrimsen, L. et al. (2003). Whose quality of life is it anyway? Alzheimer Disease and Associated Disorders, 17, 201-208.
Trigg, R., Jones, R. W. and Skevington, S. M. (2007a). Can people with mild to moderate dementia provide reliable answers about their quality of life? Age and Ageing, 36, 663-669.

Trigg, R., Skevington, S. and Jones, R. (2007b). How can we best assess the quality of life of people with dementia? The Bath Assessment of Subjective Quality of Life in Dementia (BASQID). The Gerontologist, 47, 789-797.

Walker, M. D., Salek, S. S. and Bayer, A. J. (1998). A review of quality of life in Alzheimer's disease Part 1: issues in assessing disease impact. PharmacoEconomics, 14, 499-530.

Walker, M. D., Salek, S. and Bayer, A. (2001a). The relationship between the quality of life (QQL) of dementia patients and their carers: validation of the community dementia quality of life profile. Age and Ageing, 30, 50.

Walker, M. D., Salek, S. and Bayer, A. (2001b). Assessing patient and carer quality of life (QoL) in dementia: validating the concept of a composite measure. Age and Ageing, 30, 50.

Weiner, M., Martin-Cook, K., Svetlik, D., Saine, K., Foster, B. and Fontaine, C. (2000). The quality of life in late-stage dementia (QUALID) scale. Fournal of the American Medical Directors Association, 1, 114-116.

Whitehouse, P. J. (2000). Harmonization of Dementia drug guidelines (United States and Europe): a report of the international working group for the harmonization for dementia drug guidelines. Alzheimer Disease and Associated Disorders, 14 (Suppl 1), S119-S122.

Wolak, A. et al. (2009). Transcultural adaptation and psychometric validation of a French-language version of the QoL-AD. Aging and Mental Health, 13, 593-600.

Yamamoto-Mitani, N., Abe, T., Okita, Y., Hayashi, K., Sugishita, C. and Kamata, K. (2002). Development of a Japanese quality of life instrument for older adults experiencing dementia (QLDJ). International fournal of Aging and Human Development, 55, 71-95.

Yamamoto-Mitani, N., Abe, T., Okita, Y., Hayashi, K., Sugishita, C. and Kamata, K. (2004). The impact of subject/respondent characteristics on a proxy-rated quality of life instrument for the Japanese elderly with dementia. Quality of Life Research, 13, 845-855. 